\title{
PENDEKATAN PARTISIPATORI UNTUK STRATEGI PENGEMBANGAN DESA PENYANGGA TAMAN HUTAN RAYA RADEN SOERJO
}

\author{
Erwin Ismu Wisnubroto ${ }^{1 *}$, Gerardus Jova ${ }^{1}$, Yohanes Roni ${ }^{2}$ \\ ${ }^{1}$ Program Studi Agroteknologi, Fakultas Pertanian, Universitas Tribhuwana Tunggadewi \\ ${ }^{2}$ Fakultas Ilmu Sosial dan Politik, Universitas Tribhuwana Tunggadewi \\ *Email: erwin.wisnubroto@gmail.com
}

\section{RINGKASAN}

Daerah penyangga merupakan daerah yang berada pada batas kawasan hutan lindung dan merupakan kawasan yang berfungsi untuk melindungi hutan dari aktivitas manusia yang dapat mengganggu ekosistem hutan lindung dan taman nasional. Taman Hutan Raya (Tahura) Raden Soerjo merupakan salah satu kawasan lindung yang secara administratif berada pada beberapa Kabupaten di Provinsi Jawa Timur. Beberapa permasalahan yang timbul pada kawasan desa penyangga Tahura Raden Soerjo berkaitan dengan pengelolaan kawasan pertanian dan sumberdaya hutan. Penelitian ini bertujuan untuk merancang alternatif strategi dan arahan pengembangan desa penyangga hutan di Tahura Raden Soerjo yang dapat mengurangi permasalahan pengelolaan sumberdaya hutan. Penelitian ini menggunakan pendekatan partisipatif kepada stakeholder dan pakar terkait strategi pengembangan desa penyangga hutan yang berada di Desa Wiyurejo, Kecamatan Pujon, Kabupaten Malang. Penentuan sampel pada penelitian ini dilakukan secara purposive sampling, dan pengambilan data dilakukan sebagai input pada model MULTIPOL untuk merancang berbagai alternatif strategi pengembangan desa Wiyurejo sebagai daerah penyangga Tahura Raden Soerjo. Hasil penelitian ini mengajukan prioritas kebijakan/policy yang berfokus pada pertanian multifungsi dengan prioritas program kerja membangun kawasan agrowisata, perbaikan infrastruktur dan pengembangan sumberdaya manusia melalui pelatihan dan pendidikan terkait pertanian ramah lingkungan dan agrowisata berbasis edukasi pertanian dan lingkungan.

Kata kunci: Strategic forecasting, pembangunan berkelanjutan, pertanian berkelanjutan, pertanian multifungsi.

\section{PERNYATAAN KUNCI}

- Pengembangan desa penyangga kawasan hutan lindung sebaiknya memperhatikan prioritas program kegiatan yang mengakomodasi dimensi ekonomi, sosial-budaya dan lingkungan/ekologi masyarakat desa agar fungsi kawasan peyangga hutan lindung dapat terpenuhi. 
- Pertanian multifungsi yang memadukan aktivitas pertanian komoditas tinggi berupa produk hortikultura yang telah bersertifikasi organik dan kopi dengan aktivitas non pertanian berupa pengembangan agrowisata bomestay yang mengedepankan edukasi lingkungan merupakan strategi pengembangan desa penyangga hutan yang saat ini sesuai dengan kondisi Desa Wiyurejo.

\section{REKOMENDASI KEBIJAKAN}

- Rencana program yang menjadi prioritas untuk mendukung strategi pengembangan pertanian multifungsi adalah pengembangan agrowisata bomestay, pembangunan infrastruktur pendukung dan pengembangan SDM melalui diklat untuk pertanian dan agrowisata.

- Program pengelolaan sampah perlu dilakukan di tingkat desa, dimana Pemerintah Desa Wiyurejo mengkoordinasikan daur ulang (recycle) untuk sampah anorganik pada bank-bank sampah, dan pembuatan kompos untuk sampah organik yang dapat digunakan kembali oleh petani di Desa Wiyurejo.

- $\quad$ Pengembangan agrowisata homestay di Desa Wiyurejo dapat dimulai dengan membuka jaringan dengan Amazing Bumiaji dan Kaliwatu
Learning Advanture Tourism yang telah berpengalaman di dalam membina desa wisata dengan konsep homestay edukasi pertanian ramah lingkungan di Kota Batu.

\section{PENDAHULUAN}

Hutan merupakan suatu kesatuan ekosistem berupa hamparan lahan berisi sumber daya alam hayati yang didominasi pepohonan dalam persekutuan alam dan lingkungan yaitu satu dengan lain tidak dapat dipisahkan. Berdasarkan Peraturan Pemerintah Republik Indonesia Nomor 104 Tahun 2015, hutan lindung merupakan kawasan hutan yang memiliki fungsi utama sebagai kawasan lindung untuk penyangga kehidupan yang terakit tata kelola sumber daya air, pengaturan erosi dan banjir serta mempertahankan kesuburan tanah. Oleh karena itu, penggunaan sumber daya hutan lindung akan sangat terkait dengan kondisi masyarakat yang tinggal di sekitar kawasan hutan lindung. Kawasan desa yang berada pada batas hutan lindung dikenal sebagai desa penyangga (Soemarwoto, 1985) yang berfungsi untuk menjaga aktivitas manusia di dalam pengelolaan sumber daya hutan agar tidak menyebabkan kerusakan ekosistem hutan lindung.

Taman Hutan Raya (Tahura) adalah kawasan pelestarian alam untuk tujuan koleksi tumbuhan dan/atau satwa yang alami atau buatan, jenis asli dan atau bukan asli, yang dimanfaatkan bagi kepentingan 
penelitian, ilmu pengetahuan, pendidikan, menunjang budidaya, budaya, pariwisata, dan reaksi. Dalam fungsinya, Tahura termasuk ke dalam kawasan hutan lindung. Di Indonesia terdapat berbagai Tahura seperti Tahura Pecut Merah Intan (Nangroe Aceh Darussalam), Tahura Rejo Lelo (Bengkulu), Tagura Ngurah Rai (Bali), Tagura Bonto Hari (Sulawesi Selatan), Tagura Bukit Suharto (Kalimantan Timur) Dan Tahura Raden Soerjo (Jawa Timur). Tahura Raden Soerjo menjadi perhatian dikarenakan pengelolaan Tahura ini melibatkan berbagai wilayah administratif Kabupaten di Provinsi Jawa Timur.

Pengelolaan Tahura Raden Soerjo melibatkan desa-desa yang berada di kawasan penyangga. Hasil penelitan oleh Listyarini et al, (2011) melaporkan bahwa beberapa desa yang berada pada kawasan penyangga Tahura Raden Soerjo berada pada kondisi kritis. Hal ini disebabkan karena sebagian besar masyarakat desa penyangga Tahura Raden Soejo merupakan petani yang mengolah lahan pertanian di dekat kawasan hutan (dan bahkan ada beberapa yang masuk kawasan hutan) secara intensif, sehingga menyebabkan terjadinya erosi dan kerusakan tanah. Pengelolaan kawasan desa penyangga hutan seharusnya memperhatikan kondisi sosial dan lingkungan. Pengelolaan kaawasan desa penyangga hutan seyogyanya mengacu kepada Peraturan Kementerian Lingkungan
Hidup dan Kehutanan Nomor P.43 tahun 2017 yang menegaskan bahwa rencana pengelolaan kawasan kelestarian alam harus melibatkan pemberdayaan masyarakat yang rencana pengelolaanya meliputi perencanaan, perlindungan, pengawetan, pemanfaatan, pengawasan dan pengendalian. Lebih lanjut, pemberdayaan masyarakat desa penyangga kawasan hutan tersebut juga bertujuan untuk meningkatkan kesejahteraan masyarakat desa, sehingga dapat mendukung kelestarian kawasan kelestarian alam.

Oleh sebab itu agar dapat mengembangkan suatu desa tanpa melupakan satusnya sebagai daerah penyangga dari Tahura Raden Soeryo, maka diperlukan suatu grand desain atau strategi yang memperhatikan dimensi ekonomi masyarkat yang dapat membawa keuntungan dan kesejahteraan bagi masyarakat, namun juga memperhatikan dimensi sosial dengan menggunakan kearifan lokal (local wisdom) sebagai landasan pengembangan desa, dan berwawasan lingkungan yang menerapkan prinsipprinsip ramah lingkungan untuk menjaga ekosistem dan kelestaria hutan. Penelitian ini akan mengupas lebih dalam dari potensi ekonomi, sosial dan lingkungan yang ada di kawasan desa penyangga Tahura Raden Soerjo. Penelitian ini akan mencoba untuk merancang suatu strategi dan rencana aksi yang sekiranya dapat diaplikasikan oleh 
pemerintah Desa Wiyurejo yang merupakan desa penyangga Tahura Raden Soerjo. Secara rinci tujuan dari penelitian ini adalah untuk: (1) menganalisis faktor potensi sosial, ekonomi dan lingkungan yang terdapat di Desa Wiyurejo, dan (2) merancang strategi dan rencana aksi sebagai acuan dari pengembangan Desa Wiyurejo untuk kawasan peyangga Tahura Raden Soerjo.

\section{METODOLOGI}

\section{Tempat dan Waktu Kegiatan}

Kegiatan penelitian dilakukan di Desa Wiyurejo, Kecamatan Pujon, Kabupaten Malang. Kegiatan pengumpulan data untuk penelitian ini dilaksanakan pada bulan September hingga Oktober 2019. Secara umum, kondisi bentang lahan Desa Wiyurejo merupakan daerah berlereng dengan topografi perbukitan. Peta Desa Wiyurejo disajikan pada Gambar 1.

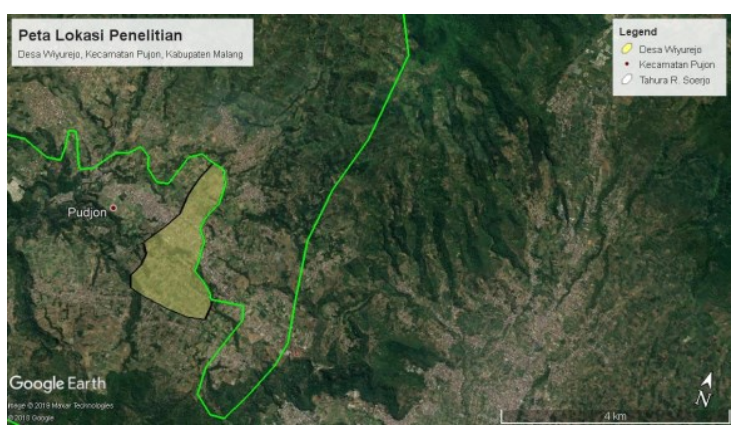

Gambar 1. Peta Desa Wiyurejo

\section{Metode Pengumpulan Data}

Metode pengumpulan data yang digunakan dalam Karya Tulis Ilmiah ini adalah dengan survey langsung ke lapangan untuk mengamati kondisi Desa Wiyurejo dan Tahura Raden Soerjo. Selain itu, untuk keperluan input data untuk analisa MULTIPOL, maka dilakukan wawancara langsung dengan beberapa pakar. Metode pemilihan pakar dilakukan secara purposive sampling, yaitu dengan menentukan siapasiapa saja yang dijadikan pakar di dalam penulisan Karya Tulis Ilmiah ini. Pakar yang dipilih adalah : (1) Pemerintah Desa Wiyurejo; (2) Kelompok Tani Tahura Raden Soerjo; (3) Komunitas Budaya dan Peduli Lingkungan "Pujon Ngalas"; (4) Dosen Program Studi Arsitektur Landskap Universitas Tribhuwana Tunggadewi Malang; (5) Dosen Program Studi Agroteknologi Universitas Tribhuwana Tunggadewi Malang; (6) Peneliti Kementerian Lingkungan Hidup dan Kehutanan; (7) Peneliti Kementerian Pertanian; (8) Staf Badan Perencanaan dan Pengembangan Daerah Pemerintah Kabupaten Malang. Proses pengambilan data melalui wawancara dan kuesioner ditunjukkan dengan dokumentasi pada Gambar 2. 

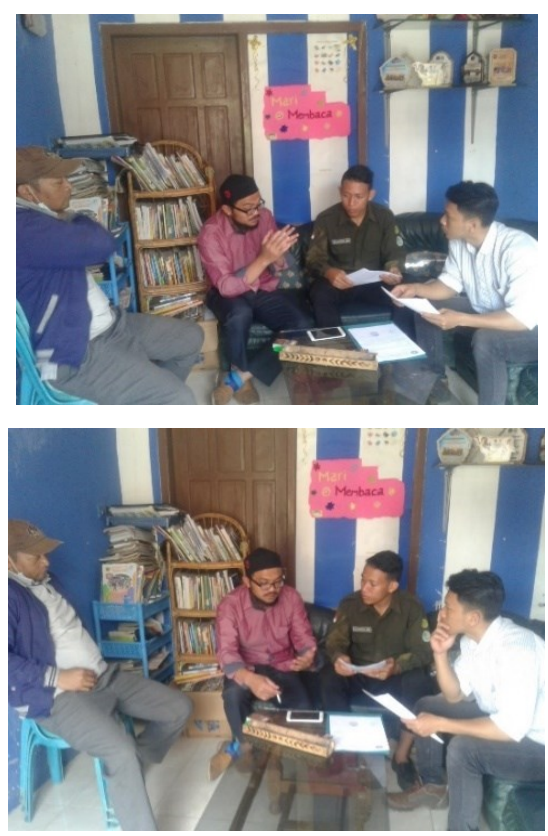

Gambar 2. Dokumentasi Wawancara Dengan Pemerintah Desa Wiyurejo

\section{Analisa Prospektif Untuk Penyusunan Strategi}

Perumusan strategi akan dilakukan dengan menggunakan pendekatan strategic forecasting dengan alat analisis MULTIPOL (Godet, 2001; Strategia, 2013). MULTIPOL merupakan alat analisis untuk pengambilan keputusan terkait dengan kebijakan dengan berdasar pada prinsip Multi Criteria Decision Analysis (Fauzi, 2019) yang dikembangkan oleh Godet (2001) dan Godet et al (2004). Perbedaan mendasar yang membedakan MULTIPOL dengan alat analisis multi kriteria lainnya adalah MULTIPOL melakukan integrasi pendekatan pertisipatif stakeholder di dalam proses penilaian kriteria, dan MULTIPOL melakukan evaluasi terhadap interaksi tiga komponen di dalam multi kriteria (Actions, Policy dan Scenarios) (Fauzi, 2019). MULTIPOL menghasilkan dua tipe evaluasi (Stratigea et al, 2013), yaitu: 1) evaluasi berbasis Actions to Policy; dan 2) evaluasi berbasis Policy to Scenario. Interaksi dari ke tiga komponen tersebut digambarkan pada Gambar 3. Tahapan analisa MULTIPOL disajikan pada Gambar 4.

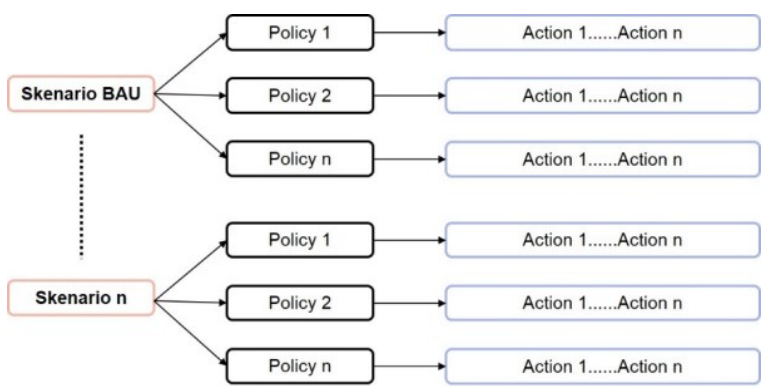

Gambar 3. Interaksi Strategi (Policy) dan Rencana Aksi (Action)

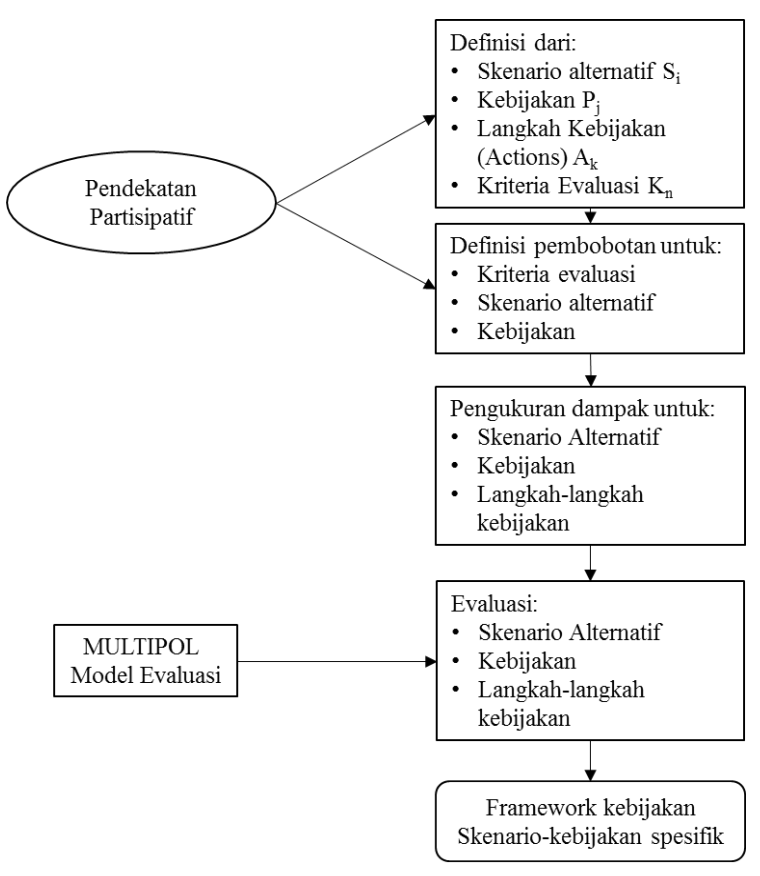

Gambar 4. Tahapan Analisa MULTIPOL

\section{SITUASI TERKINI}

Taman Hutan Raya Raden Soerjo merupakan Tahura yang terletak di Provinsi Jawa Timur, dan meliputi wilayah administratif Kabupaten Malang, Kabupaten Jombang, Kabupaten 
Mojokerto, Kota Batu dan Kabupaten Pasuruan (Listyarini et al, 2011). Di sekitar Tahura ini banyak penduduk desa yang bermukim, sebab sebagaimana telah diketahui bersama bahwa hutan merupakan tempat ditemukannya banyak sumber daya alam yang dapat digunakan untuk menopang kehidupan masyarakat. Salah satu desa yang bermukim di sekitar Tahura Raden Soerjo adalah Desa Wiyurejo, Kecamatan Pujon, Kabupaten Malang.

Desa Wiyurejo memiliki luas 320,20 ha dan penggunaan lahan didominasi oleh lahan pertanian (102,5 ha lahan sawah dengan sumber pengairan; dan 203,7 ha lahan pertanian lahan kering). Sebagian besar penduduk Desa Wiyurejo memiliki mata pencaharian sebagai petani dan buruh tani. Lahan pertanian di Desa Wiyurejo didominasi oleh komoditas hortikultura seperti sayur-sayuran, dan sebagian lahan perkebunan kopi. Desa Wiyurejo memiliki industri pengolahan kayu yang mengolah sumber kayu dari kawasan Tahura Raden Soerjo.

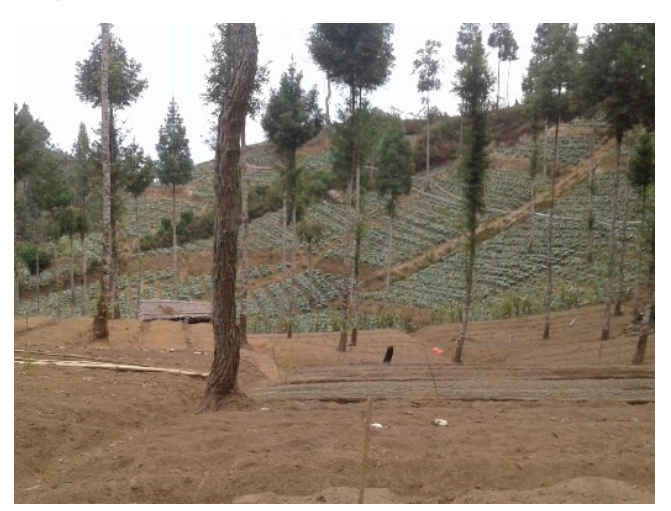

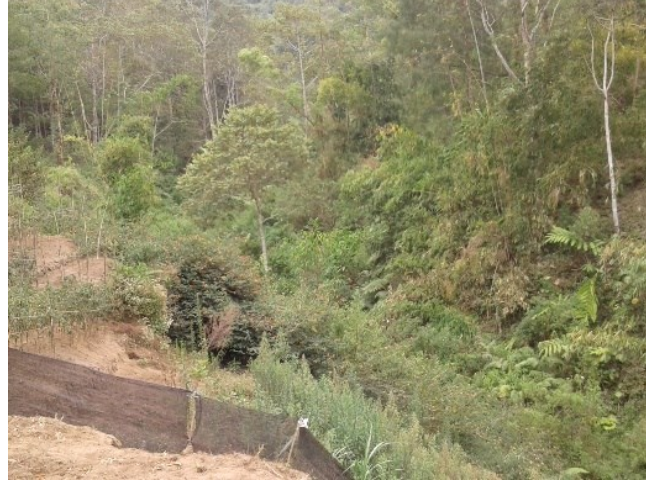

Gambar 5. Kondisi Lahan di Tahura Raden Soerjo di Kawasan Desa Wiyurejo

Desa Wiyurejo berbatasan langsung dengan Tahura Raden Soerjo, oleh sebab itu sangat penting bagi Desa Wiyurejo yang memiliki peran sebagai desa penyangga untuk mampu menyangga kelestarian hutan Tahura Raden Soerjo terutama dari tekanan dan gangguan eksploitasi hasil hutan kayu dan non kayu secara berlebihan. Hasil survey di lahan menunjukkan bahwa ditemukan banyak lahan pertanian dibuka pada kawasan hutan (Gambar 5). Hal ini dapat menyebabkan terjadinya kerusakan lingkungan seperti erosi dan kehilangan hara tanah, yang jika tidak segera diatasi dapat menyebabkan terjadinya degradasi lahan pada kawasan Tahura Raden Soerjo.

Rencana pengembangan desa Wiyurejo perlu memprioritaskan kehidupan masyarakat dapat mencapai kesejahteraan, dengan memperhatikan potensi ekonomi, pelestarian kearifan lokal dalam kondisi sosial-budaya dan mengedepankan pelestarian ekosistem hutan dan lingkungan. Oleh sebab itu dibutuhkan strategi 
pengembangan Desa Wiyurejo sebagai desa penyangga Tahura Raden Soerjo yang berorientasi pada ekonomi masyarakat tanpa mengabaikan aspek kelestarian lingkungan dan kearifan lokal. Penelitian ini mengajukan lima komponen strategi pengembangan Desa Wiyurejo sebagai desa penyangga Tahura Raden Soerjo, yaitu:

1. Pengembangan pertanian organik yang dapat menghasilkan komoditas pertanian bernilai tinggi.

2. Konservasi Sumberdaya Hutan untuk menjaga kelestarian lingkungan.

3. Konservasi Sumberdaya Air yang berada kawasan hutan.

4. Pengembangan Ekowisata dan Wisata Edukasi yang mengedepankan pendidikan dan pengalaman untuk melestarikan lingkungan.

5. Pengelolaan Sampah di tingkat desa, mengedepankan prinsip recycle untuk sampah anorganik yang masih dapat digunakan kembali/daur ulang, dan prinsip composting untuk mengolah sampah-sampah organik menjadi pupuk kompos yang dapat digunakan oleh masyarakat Desa Wiyurejo.

\section{ANALISIS DAN ALTERNATIF SOLUSI}

Pengembangan Desa Wiyurejo sebagai kawasan penyangga akan memerlukan analisis awal mengenai kondisi sosial-ekonomi, dan lingkungan di Desa Wiyurejo. Hal ini dilakukan sebagai dasar dari penyusunan strategi pengembangan Desa Wiyurejo untuk kawasan penyangga hutan, maka kami mengusulkan paradigma pembangunan berkelanjutan yang mengusung tiga dimensi keberlanjutan, yaitu keberlanjutan di bidang ekonomi, sosial dan lingkungan/ekologi. Perlu diperhatikan bahwa agar Desa Wiyurejo mampu mempertahankan fungsi penyangga untuk Tahura Raden Soerjo, hal yang pertama yang harus diperhatikan adalah keberlanjutan pada dimensi ekonomi. Sebagaimana telah disampaikan pada ulasan di atas, sebagian besar masyarakat Desa Wiyurejo adalah petani yang juga melakukan aktivitas di dalam hutan. Oleh karena itu, sumber mata pencaharian utama petani di Desa Wiyurejo harus lebih didukung, agar mampu meningkatkan nilai dari kegiatan pertanian tidak hanya produksi saja namun juga nilai tambah yang lain.

Dengan memperkuat dimensi ekonomi petani di Desa Wiyurejo, diharapkan petani akan lebih mendapatkan hasil yang baik dari lahan pertaniannya, sehingga dapat mengurangi terjadinya perambahan hutan, baik untuk hasil kayu maupun pembukaan lahan hutan untuk kegiatan pertanian. Dengan demikian, maka diharapkan strategi penguatan petani yang mendahulukan dimensi ekonomi akan mampu mendukung strategi pada dimensi sosial dan lingkungan/ekologi. Dari hasil pengamatan awal terhadap kondisi Desa 
Wiyurejo, kami mengajukan arah pengembangan (Strategi Pengembangan/

Policy) Desa Wiyurejo untuk:

1. Pertanian multi-fungsi, yaitu pengembangan kegiatan pertanian yang menggabungkan produksi hasil pertanian komoditas tinggi dengan kegiatan agro-wisata. Strategi ini telah dikembangkan pada beberapa penelitian untuk kawasan pedesaan, diantaranya oleh Stratigea et al, (2013). Penekanan dari strategi ini adalah pengembangan kawasan pertanian yang mampu menghasilkan komoditas pertanian bernilai tinggi dengan penerapan teknologi ramah lingkungan, dan juga nilai tambah dari aktivitas non pertanian seperti pengembangan agrowisata pertanian.

2. Pelestarian nilai budaya dan sosial kemasyarakatan, yaitu pengembangan kegiatan budaya di Desa Wiyurejo dalam wadah aktivitas Pujon Ngalas. Nilai-nilai kearifan lokal yang dikembangkan oleh penduduk Desa Wiyurejo menjadi daya tarik dan kelebihan di dalam pelestarian budaya yang memadukan kelestarian hutan dan budaya.

3. Konservasi sumberdaya hutan dan lingkungan, yaitu pengembangan kegiatan hutan yang mengedepankan konservasi hutan (penanaman pohon dan bambu) serta konservasi sumberdaya air. Fungsi Tahura Raden Soerjo bagi masyarakat di Desa Wiyurejo sangat penting, tidak hanya sebagai sumber daya hutan non kayu, namun juga sebagai sumber air. Oleh karena itu diperlukan upaya pelestarian sumberdaya hutan dan sumberdaya air melalui konservasi dengan penanaman pohon dan bambu, serta kesadaran lingkungan di dalam mengelola sumberdaya air. Pengelolaan sampah di tingkat desa juga terkait dengan strategi konservasi sumberdaya hutan dan lingkungan.

Untuk dapat mewujudkan strategi pengembangan (Policy) tersebut, maka perlu disusun beberapa rencana program kerja (Action) yang dapat dilaksanakan oleh Pemerintah Desa Wiyurejo. Rencana program kerja yang diajukan merupakan hasil diskusi dengan para pakar melalui proses wawancara. Usulan rencana program kerja untuk mewujudkan strategi pengembangan disajikan pada Tabel 1 .

Usulan rencana program kerja yang disajikan pada Tabel 1 merupakan hasil diskusi dengan para pakar yang memperhatikan kemudahan program kerja yang dapat dilakukan oleh Pemerintah Desa Wiyurejo. Untuk mengukur apakah rencana program kerja tersebut dapat dilaksanakan, maka ditentukan kriteria/indikator yang diharapkan dapat terwujud dari pelaksanaan program kerja tersebut. Penentuan 
kriteria/indikator juga melalui proses diskusi dan wawancara dengan para pakar.

Kriteria/indikator yang dihasilkan dari hasil

diskusi tersebut disajikan pada Tabel 2.

Untuk mengetahui prioritas rencana program kerja mana yang harus didahulukan, maka kami menggunakan metode Multi-Criteria Decision Analysis (MCDA) dengan alat analisis metode
MULTIPOL. Dengan metode MULTIPOL ini, para pakar akan memberikan penilaian terhadap prioritas rencana program kerja untuk mewujudkan strategi pengembangan Desa Wiyurejo yang paling sesuai untuk kondisi saat ini.

Tabel 1. Usulan Rencana Program Kerja (Action) Pengembangan Desa Wiyurejo

\begin{tabular}{|c|c|c|}
\hline No & Program Kerja & Keterangan \\
\hline 1 & $\begin{array}{l}\text { Pengembangan } \\
\text { Pertanian Organik }\end{array}$ & $\begin{array}{l}\text { Pengembangan komoditas pertanian yang telah bersertifikasi } \\
\text { organik }\end{array}$ \\
\hline 2 & $\begin{array}{l}\text { Pengembangan Agro- } \\
\text { tourism }\end{array}$ & $\begin{array}{l}\text { Pengembangan agrowisata model homestay yang memberikan } \\
\text { pengalaman dan edukasi Bertani }\end{array}$ \\
\hline 3 & $\begin{array}{l}\text { Pengembangan } \\
\text { Infrastruktur Desa }\end{array}$ & Pembangunan dan penguatan infrastruktur pedesaan \\
\hline 4 & $\begin{array}{l}\text { Pengembangan } \\
\text { Sumberdaya Manusia }\end{array}$ & $\begin{array}{l}\text { Peningkatan kemampuan (skill) dan pengetahuan masyarakat desa } \\
\text { untuk mendukung agrowisata dan pertanian organik }\end{array}$ \\
\hline 5 & $\begin{array}{l}\text { Pengembangan } \\
\text { Komunikasi dan } \\
\text { Teknologi }\end{array}$ & $\begin{array}{l}\text { Pengembangan dan peningkatan jaringan informasi, komunikasi } \\
\text { dan teknologi }\end{array}$ \\
\hline 6 & $\begin{array}{l}\text { Pengelolaan sampah } \\
\text { desa }\end{array}$ & $\begin{array}{l}\text { Pengelolaan sampah di tingkat desa dengan bank sampah untuk } \\
\text { jenis sampah yang dapat di daur ulang kembali dan pengolahan } \\
\text { sampah organik menjadi pupuk kompos }\end{array}$ \\
\hline
\end{tabular}

Tabel 2. Kriteria atau Indikator dari Rencana Program kerja

\begin{tabular}{|c|c|c|}
\hline No & Indikator & Keterangan \\
\hline 1 & $\begin{array}{l}\text { Peningkatan } \\
\text { pendapatan }\end{array}$ & $\begin{array}{l}\text { Peningkatan pendapatan petani baik dari hasil pertanian maupun hasil } \\
\text { non-pertanian }\end{array}$ \\
\hline 2 & $\begin{array}{l}\text { Penyerapan tenaga } \\
\text { kerja }\end{array}$ & $\begin{array}{l}\text { Jumlah tenaga kerja di Desa Wiyurejo yang terserap pada kegiatan dari } \\
\text { rencana program kerja }\end{array}$ \\
\hline 3 & $\begin{array}{l}\text { Tumbuhnya usaha } \\
\text { baru }\end{array}$ & $\begin{array}{l}\text { Jumlah usaha baru yang tumbuh akibat pelaksanaan rencana program } \\
\text { kerja }\end{array}$ \\
\hline 4 & $\begin{array}{l}\text { Pelestarian } \\
\text { sumberdaya air }\end{array}$ & $\begin{array}{l}\text { Tercapainya upaya pelestarian sumberdaya air yang berada pada } \\
\text { kawasan Tahura Raden Soerjo }\end{array}$ \\
\hline 5 & $\begin{array}{l}\text { Peningkatan jaringan } \\
\text { infrastruktur }\end{array}$ & $\begin{array}{l}\text { Peningkatan kondisi dan fasilitas infrastruktur yang dapat digunakan } \\
\text { oleh warga Desa Wiyurejo, utamanya petani untuk aktivitas dan } \\
\text { kegiatan mereka }\end{array}$ \\
\hline 6 & $\begin{array}{l}\text { Kegiatan wisata } \\
\text { budaya yang } \\
\text { dilaksanakan }\end{array}$ & $\begin{array}{l}\text { Tercapainya upaya pelestarian kebudayaan Desa Wiyurejo yang } \\
\text { mengedepankan kearifan lokal di dalam pemanfaatan sumberdaya } \\
\text { hutan dan air yang diwujudkan dalam bentuk kegiatan-kegiatan festival } \\
\text { budaya }\end{array}$ \\
\hline
\end{tabular}

Hasil evaluasi rencana program kerja dengan metode MULTIPOL disajikan pada
Tabel 3. Hasil analisa tersebut menunjukkan bahwa Rencana program kerja 
pengembangan agrowisata pertanian infrastruktur pertanian untuk mendukung memiliki nilai rerata tertinggi $(17,7)$, dengan aktivitas masyarakat Desa Wiyurejo. Setelah nilai simpangan baku yang rendah $(0,4$; dua prioritas utama tersebut, Maka perlu dibawah 1) sehingga menempati peringkat dilakukan berbagai pelatihan dan pertama. Hal ini menunjukkan bahwa para pakar sepakat bahwa pengembangan pendidikan (Diklat) untuk pengembangan konsep agrowisata menjadi prioritas utama yang harus dilakukan. Prioritas ke dua yang dinilai penting adalah pembangunan kapasitas Sumberdaya Manusia (SDM) untuk mendukung pertanian ramah lingkungan dan agrowisata pertanian yang akan terbentuk di Desa Wiyurejo.

Tabel 3. Hasil Evaluasi Rencana Program Kerja

\begin{tabular}{|c|c|c|c|c|c|c|}
\hline \multirow[b]{2}{*}{$\begin{array}{c}\text { Actions (Program } \\
\text { kerja) }\end{array}$} & \multicolumn{3}{|c|}{ Policy (Strategi) } & \multirow[b]{2}{*}{ Nilai rerata } & \multirow[b]{2}{*}{$\begin{array}{c}\text { Simpangan } \\
\text { Baku }\end{array}$} & \multirow[b]{2}{*}{$\begin{array}{l}\text { Peringkat } \\
\text { (Prioritas) }\end{array}$} \\
\hline & $\begin{array}{l}\text { Pertanian } \\
\text { Multifungsi }\end{array}$ & $\begin{array}{c}\text { Kearifan } \\
\text { lokal }\end{array}$ & $\begin{array}{c}\text { Konservasi } \\
\text { Sumberdaya } \\
\text { Hutan }\end{array}$ & & & \\
\hline $\begin{array}{l}\text { Pengembangan } \\
\text { pertanian organik }\end{array}$ & 12,5 & 12 & 12,3 & 12,3 & 0,2 & 6 \\
\hline $\begin{array}{l}\text { Pengembangan } \\
\text { agrowisata } \\
\text { berbasis edukasi }\end{array}$ & 18,2 & 17,5 & 17,3 & 17,7 & 0,4 & 1 \\
\hline $\begin{array}{l}\text { Pengembangan } \\
\text { infrastruktur } \\
\text { Desa }\end{array}$ & 17,3 & 16,6 & 16,5 & 16,8 & 0,3 & 3 \\
\hline $\begin{array}{l}\text { Peningkatan } \\
\text { kualitas sumber } \\
\text { daya manusia }\end{array}$ & 16,9 & 16,9 & 16,8 & 16,9 & 0,1 & 2 \\
\hline $\begin{array}{l}\text { Pengembangan } \\
\text { teknologi } \\
\text { informasi dan } \\
\text { sosial media }\end{array}$ & 15,8 & 15,4 & 15,2 & 15,5 & 0,2 & 4 \\
\hline $\begin{array}{l}\text { Pengolahan } \\
\text { sampah desa } \\
\text { (Recycle dan } \\
\text { Kompos) }\end{array}$ & 14,4 & 14 & 14,4 & 14,2 & 0,2 & 5 \\
\hline
\end{tabular}


Untuk melihat hubungan antara strategi dan rencana program yang diusulkan kepada Pemerintah Desa Wiyurejo, maka dilakukan analisa closeness map dengan metode MULTIPOL. Hasil analisa closeness map yang menggambarkan keterkaitan antara strategi dan rencana program disajikan pada Gambar 6. Dapat dilihat bahwa strategi pengembangan pertanian multifungsi lebih dekat kepada program pengembangan agrowisata pertanian dan infrastruktur desa. Hal ini menunjukkan bahwa Desa Wiyurejo masih memerlukan infrastruktur pendukung pertanian dan agrowisata pertanian agar dapat bersaing dengan Desa-desa wisata lain di Kecamatan Pujon.

Hasil analisa closeness map juga menunjukkan bahwa strategi konservasi sumberdaya hutan dan air dekat dengan program pertanian organik dan program pengelolaan sampah desa. Dengan demikian, maka Pemerintah Desa Wiyurejo disarankan untuk memulai inisiatif pengelolaan sampah Desa, yaitu dengan terlebih dahulu menghimbau masyarakat desa untuk memilah sampah organik dan sampah anorganik. Sampah anorganik seperti plastik, kertas, dan kardus dapat dikumpulkan pada bank sampah yang dikelola desa, yang nantinya akan dapat di daur ulang kembali atau dikumpulkan pada bank-bank sampah di di tingkat kecamatan. Sedangkan untuk sampah organik seperti sisa makanan dan sampah dapur, dapat diolah kembali menjadi kompos dengan mencampur sampah organik dengan sisa tanaman maupun kotoran hewan ternak untuk menjadi pupuk kompos. Pengelolaan kompos ini diusulkan dikelola pada tingkat desa, sehingga produk hasil pengolahan kompos dapat didistribusikan kembali kepada petani-petani di Desa Wiyurejo. 


\section{Action/policy closeness map}

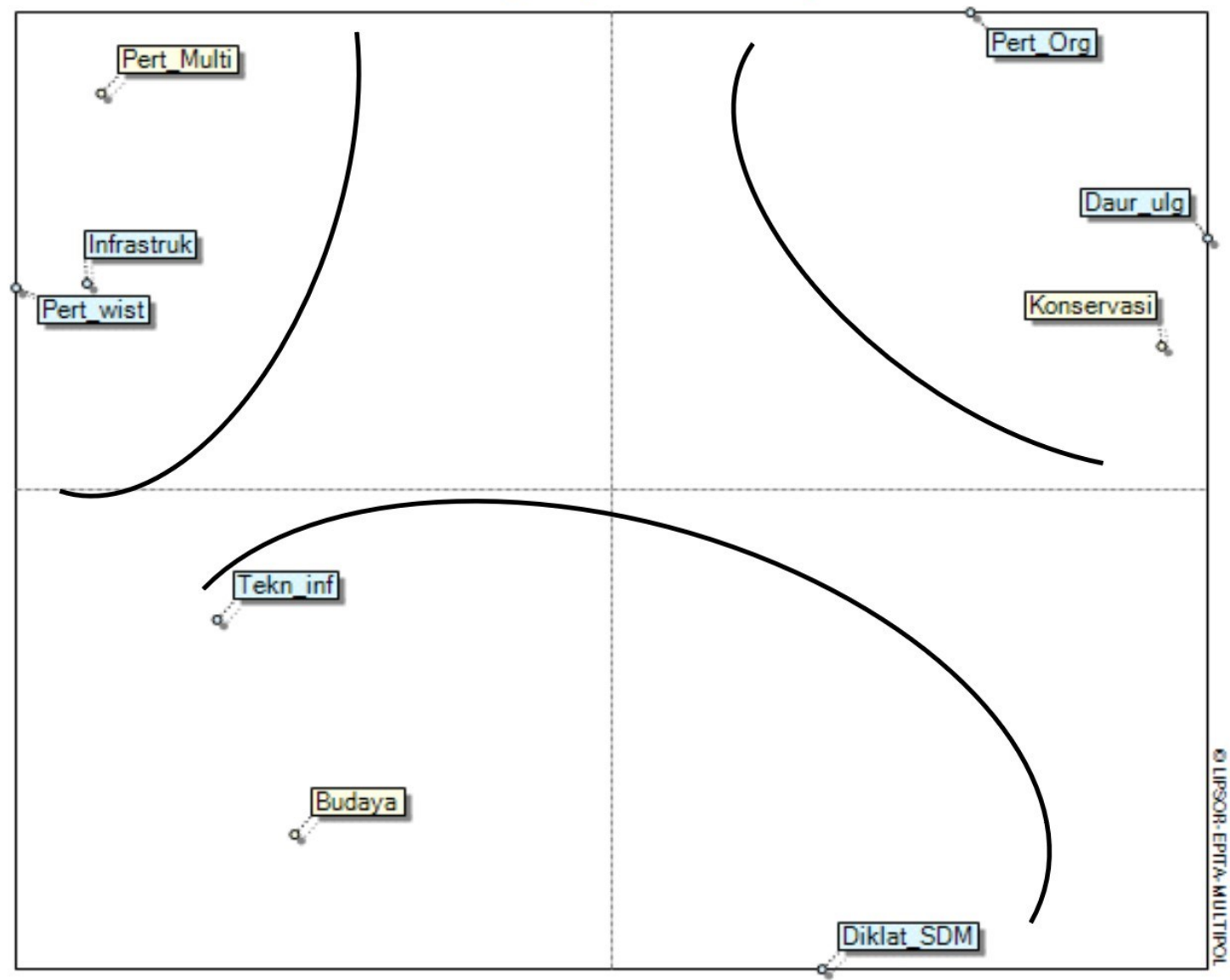

Gambar 6. Keterkaitan Strategi dan Rencana Aksi

Tabel 4. Hasil Evaluasi Strategi

\begin{tabular}{|c|c|c|c|c|c|}
\hline \multirow[b]{2}{*}{ Policy (Strategi) } & \multicolumn{2}{|c|}{ Skenario } & \multirow[b]{2}{*}{ Nilai rerata } & \multirow[b]{2}{*}{$\begin{array}{c}\text { Simpangan } \\
\text { Baku }\end{array}$} & \multirow[b]{2}{*}{$\begin{array}{l}\text { Peringkat } \\
\text { (Prioritas) }\end{array}$} \\
\hline & $\begin{array}{l}\text { Supply } \\
\text { Side }\end{array}$ & $\begin{array}{l}\text { Demand } \\
\text { Side }\end{array}$ & & & \\
\hline Pertanian Multifungsi & 16 & 18,2 & 17,1 & 1,1 & 1 \\
\hline Kearifan Lokal & 17,1 & 16,9 & 17 & 0,1 & 2 \\
\hline Konservasi Sumberdaya Hutan & 16,4 & 14,2 & 15,3 & 1,1 & 3 \\
\hline
\end{tabular}

Dari hasil analisa prioritas strategi pengembangan desa dengan metode MULTIPOL, didapatkan peringkat prioritas strategi yang harus dilakukan berdasarkan hasil wawancara dengan para pakar (Tabel 4). Skenario pengembangan wilaya pedesaan dapat didekati melalui skenario berbasis sisi permintaan (Demand
Side) dan skenario berbasis sisi penawaran (Supply Side) (Deaton dan Nelson 1992). Melihat nilai rerata dari hasil evaluasi strategi (Tabel 4), maka didapatkan bahwa strategi prioritas pengembangan Desa Wiyurejo sebagai kawasan penyangga yang paling tepat dilakukan adalah dengan kebijakan pengembangan Pertanian 
Multifungsi (nilai rerata 17,1 dan simpangan baku 1,1).

Penelitian yang dilakukan oleh Zasada (2011) mengemukakan bahwa pertanian multi fungsi menggunakan berbagai strategi penggunaan lahan yang meliputi diversifikasi kegiatan pertanian dan nonpertanian, mengembangkan proses produksi hasil pertanian, dan upaya manajemen konservasi lahan. Konsep pertanian multi fungsi tidak memiliki arti diversifikasi produk pertanian dan peningkatan kegiatan non pertanian (offfarm) (Pribadi dan Pauleit, 2015), namun lebih menekankan kepada meningkatkan fungsi pertanian di luar dari penyediaan pangan. Pertanian multi fungsi yang dikembangkan di Desa Wiyurejo akan meliputi pertanian ramah lingkungan dengan komoditas bernilai tinggi seperti produk hortikultura dan tanaman perkebunan seperti kopi, dan juga pengembangan agrowisata dalam bentuk homestay yang mengusung farming experience dan kelestarian alam. Pengembangan pertanian multifungsi tersebut diharapkan mampu menjaga kelestarian lingkungan dan meminimalisasi kerusakan lingkungan, sehingga dapat mendukung fungsi kawasan penyangga bagi kawasan Tahura Raden Soerjo.

Hasil evaluasi strategi pengembangan Desa Wiyurejo menunjukkan bahwa pada strategi Pertanian Multifungsi unggul pada kondisi skenario Supply Side (pendekatan investasi pada SDM, dan pembentukan modal) (Gambar 7). Sedangkan strategi wisata budaya unggul pada kondisi skenario Demand Side (pendekatan investasi ekonomi) (Gambar 7). Hal ini menunjukkan bahwa jika Desa Wiyurejo ingin lebih fokus pada pengembangan wisata budaya, maka diperlukan injeksi ekonomi (investasi dalam bentuk uang) yang lebih tinggi dibandingkan strategi pertanian multifungsi maupun konservasi sumberdaya hutan dan air. 


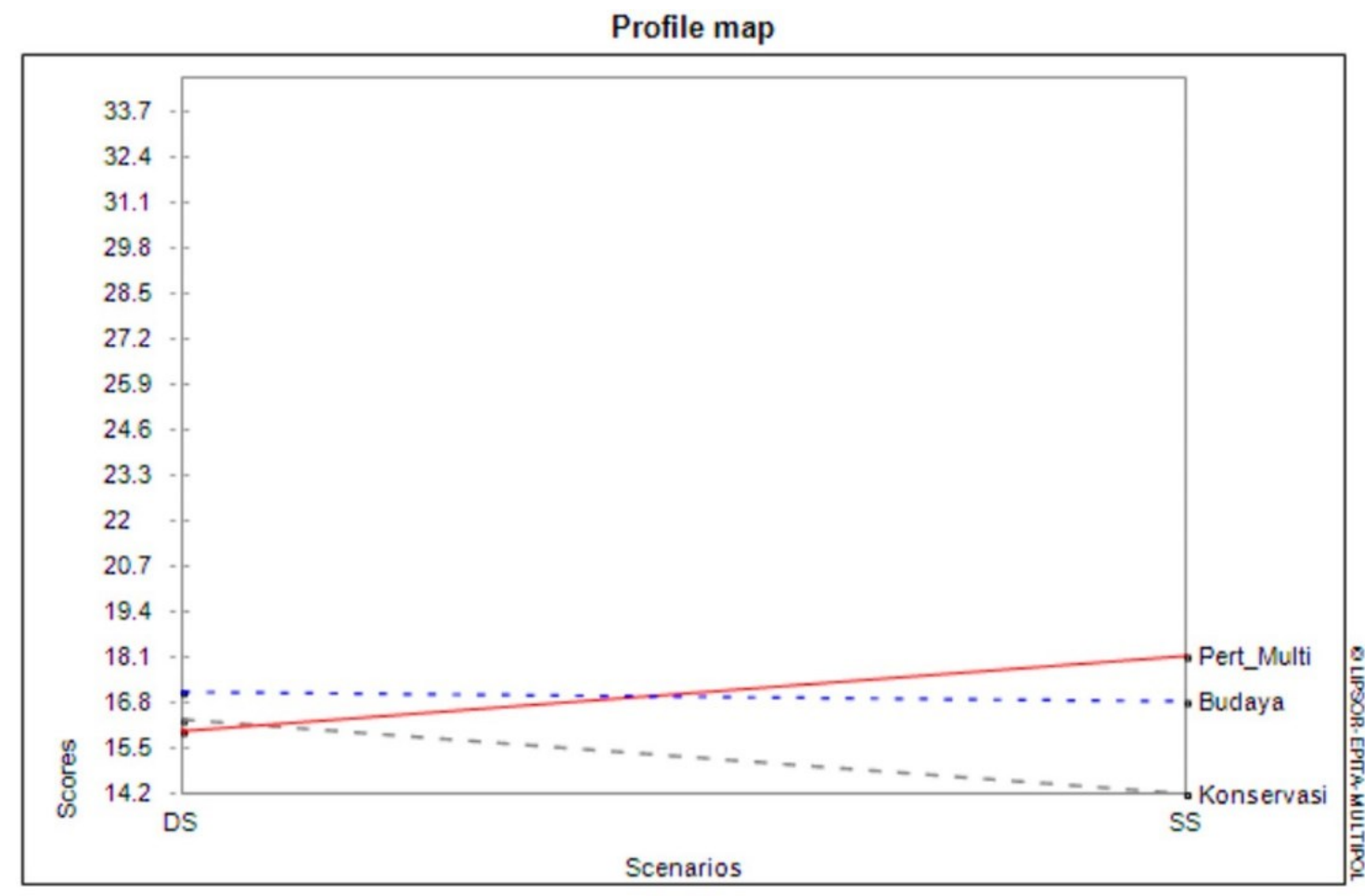

Gambar 7. Profile Map Skenario Pengembangan Desa Wiyurejo

Gambar 8 menyajikan alternatif jalur kebijakan yang dapat dilakukan oleh Pemerintah Desa Wiyurejo di dalam pengembangan desa melalui berbagai program kerja yang sesuai dengan strategi. Hasil penelitian ini merumuskan strategi pengembangan Desa Wiyurejo untuk fokus pertanian multifungsi dengan skenario supply side maka rencana program kerja yang dapat dilakukan adalah dengan penguatan infrastruktur desa dan pengembangan agrowisata berbasis bomestay edukasi pertanian dan lingkungan. Sedangkan pada strategi pengembangan desa untuk fokus kearifan lokal dan pelestarian budaya baik pada skenario demand side maupun supply side, maka rencana program yang dapat dilakukan adalah pemanfaatan teknologi informasi dan sosial media sebagai salah satu alat untuk mengenalkan dan mempromosikan kegiatan-kegiatan sosialbudaya di Desa Wiyurejo. Selain itu, rencana program kerja pendidikan dan pelatihan untuk pengembangan Sumberdaya Manusia (SDM) juga dianjurkan untuk dilakukan oleh Pemerintah Desa Wiyurejo. Strategi pengembangan yang hanya dapat dikembangkan pada kondisi skenario supply side adalah konservasi sumberdaya hutan dan lingkungan, yang dapat dilakukan dengan fokus rencana kegiatan pengembangan pertanian organik dan pengelolaan sampah desa dengan bank sampah dan pengolahan kompos. 


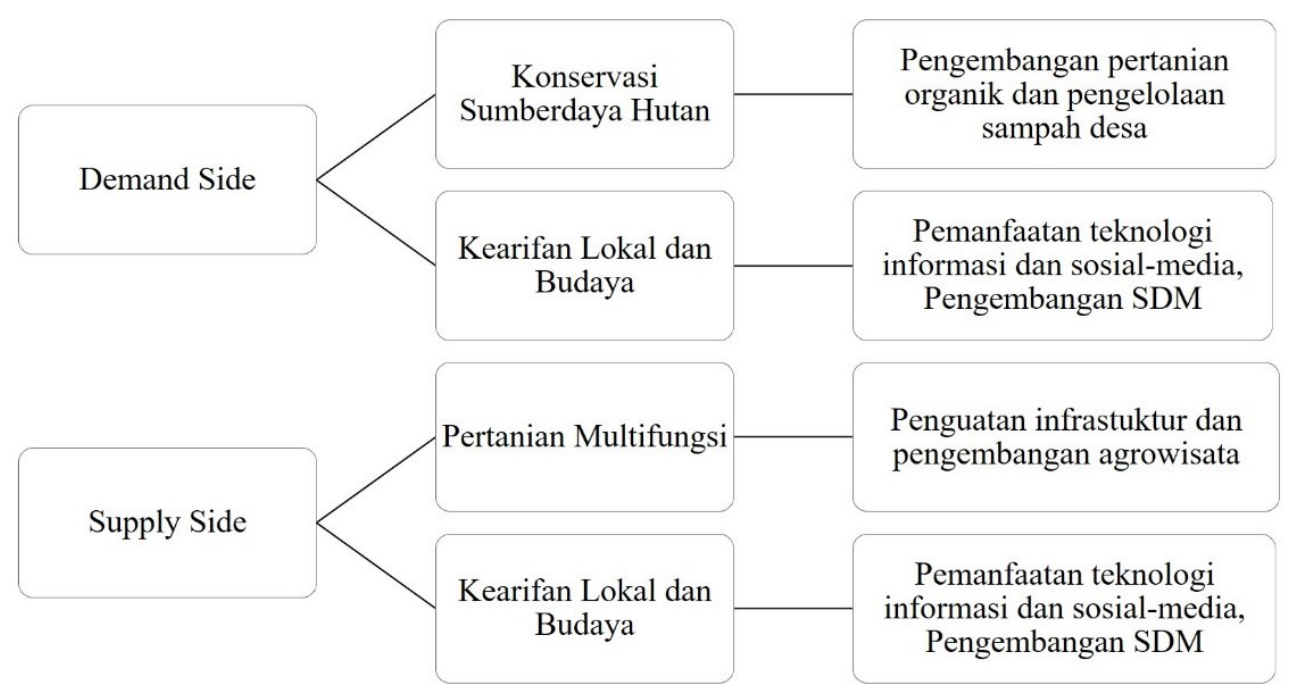

Gambar 8. Potensi Jalur Kebijakan (Strategi) dan Rencana Program Kerja

\section{REFERENSI}

Deaton, B.J., Nelson, G.L. 1992. Conceptual underpinnings of policy analysis for rural development. Journal of Agricultural and Applied Economics. 24(1): 87-99.

Fauzi, A. 2019. Teknik Analisis Keberlanjutan. Jakarta (ID): PT. Gramedia Pustaka Utama.

Godet, M., Monti, R., Meunier, F., Roubelat, F. 2004. Scenarios and Strategies: A toolbox for Problem Solving. Cabiers du LIPSOR, LISOR Working Papers. Laboratoire d'Investigation en Prospective, Stratigie et Organisation.

Godet, M. 2001. Creating Futures: Scenario Planning as a strategic management tool. Washington, DC: Economica. Economica Brookings diffusion.

Kementerian Lingkungan Hidup dan Kehutanan. 2017. Peraturan Kementerian Lingkungan Hidup dan Kehutanan Republik Indonesia Noor

P.43/MENLHK/SETJEN/KUM. 1/6/2017 Tentang Pemberdayaan Masyarakat di Sekitar Kawasan Suaka Alam dan Kawasan Pelestarian Alam.
Listyarini, L., Sari, N., Sutikno, F.R. 2011. Optimalisasi Fungsi Daerah Penyangga Kawasan Taman Hutan Raya Raden Soerjo (Studi Kasus: Desa Sumber Brantas Kota Batu). Jurnal Tata Kota dan Daerah. 3(1): 47-53.

Pemerintah Republik Indonesia. 2015. Peraturan Pemerintah Republik Indonesia Nomor 104 Tahun 2015 Tentang Tata Cara Perubahan Peruntukan Dan Fungsi Kawasan Hutan.

Pribadi, D.O., Pauleit, S. 2015. The dynamics of peri-urban agriculture during rapid urbanization of Jabodetabek Metropolitan Area. Land Use Policy. 48: 13-24.

Soemarwoto, Otto. 1985. Ekologi, Lingkungan Hidup dan Pembangunan. Jakarta: Djambatan.

Stratigea, A. 2013. Participatory policy making in foresight studies at the regional level-A methodological approach. Regional Science Inquiry. 5(1): 145-160.

Zasada, I. 2011. Multifunctional peri-urban agriculture-A review of societal demands and the provision of goods and services by farming. Land Use Policy. 28(4): 639-648. 